\title{
An Inventory Model for Weibull Distributed Deteriorating Items Under Ramp Type Demand and Permissible Trade Credit Policy
}

\author{
Dr. Biswaranjan Mandal ${ }^{1} \quad$ Dr. Milan Biswas ${ }^{2} \quad$ Dr. Nabakumar Ghosh ${ }^{2}$ \\ 1.Associate Professor of Mathematics, Acharya Jagadish Chandra Bose College, Kolkata, West Bengal, India \\ 2.Assistant Professor of Mathematics, Acharya Jagadish Chandra Bose College, Kolkata, West Bengal, India
}

\begin{abstract}
In a classical inventory economic order quantity (EOQ) model, the stock is depleted due to both market demand and deterioration. Many inventory models are developed for items under variable rate of deterioration. The two parameter Weibull distributed term is a representation of constant, time dependent linear and non-linear, increasing and decreasing rate of deterioration. Again the demand rate is assumed here as time dependent in beginning of cycle and then becomes constant as passage of time. Shortages are allowed and fully backlogged. Moreover the trade credit policy is a win-win payment strategy for sharing profit in the inventory system. This present paper deals with a replenishment policy assuming two parameter Weibull distributed deteriorating items, demand rate a ramp type function of time under permissible trade credit policy. Finally several numerical examples are given to illustrate the model and some particular cases are also discussed along with its' illustrations along with concluding remarks.
\end{abstract}

Keywords: Inventory, Weibull distribution, deterioration, ramp type, trade credit and shortages.

Subject classification: AMS Classification No. 90B05

DOI: $10.7176 / \mathrm{EJBM} / 13-19-03$

Publication date:October $31^{\text {st }} 2021$

\section{Introduction}

In a classical EOQ model and in view of a real life situation, inventory is depleted due to both market demand and deterioration. So many decision makers are always confined for making policies to control and maintain inventories of deteriorating items. Researchers like Covert and Philip [1973], A. K. Jalan et al[1996], T. Chakrabarty et al[1998], K.S.Wu (2002), Anil Kumar Sharma[2012], Biswaranjan Mandal[2010],[2020] and many are developing different inventory models assuming items which deteriorate at constant or vary over time. In this paper, the deterioration rate is followed by two parameter Weibull distributed which is a representation of constant, time dependent linear and non-linear, increasing and decreasing function of time.

The assumption of constant demand is not always appropriate for many inventory models. When a new brand of goods like new branded car, dolls, advanced computer devices etc come in the market, the initial demand is mostly increasing with time and then ultimately stabilizes as constant. This pattern of demand is called a ramp type demand of time. It is mostly seen in the present field of economy in any kind of business sectors. In this field, researchers like W.A. Donaldson[1977], E.A. Silver[1979], R.M. Hill[1979], M. Mallick [2018], Biswaranjan Mandal [2020] etc are mentioned a few. The present model assumes such type of ram type demand function of time.

Traditionally, the supplier is paid for the items as soon as the items are received by the purchaser. But a permissible trade credit policy is developed where the supplier may provide a delay period to the customer if the outstanding amount is paid within a fixed settled period. No interest is charged during this period. Moreover beyond this period of time, the interest is charged by the supplier. This trade credit policy is a win-win payment strategy for sharing profit in the inventory system. In this context, few researchers S.P. Aggarwal et al [1995], H. J. Chang et al [2002], Y.F. Huang [2007], H. C. Chang[2009], G. Li et al[2014], N.P. Behera [2017], Biswaranjan Mandal[2021] etc. are noteworthy.

This present study investigates a situation in which replenishment policy is assumed with two parameter Weibull distributed deteriorating items, demand rate a ramp type function of time under permissible trade credit policy. Shortages are allowed and which is fully backlogged. Finally several numerical examples are given to illustrate the model and some particular cases are also discussed along with concluding remarks.

\section{Assumptions and Notations :}

The following fundamental assumptions and notations used in the present paper are made:

\section{Assumptions:}

(i). Replenishment rate is infinite but size is finite.

(ii). Lead time is zero.

(iii). The time horizon is finite.

(iv). There is no repair or replacement of the deteriorated items occurring during the cycle. 
(v). Deterioration occur when the item is effectively in stock.

(vi). The deterioration rate function for two parameter Weibull distribution is

$$
\theta(\mathrm{t})=\alpha \beta t^{\beta-1}, 0 \leq \alpha<<1, \beta>0, t>0 .
$$

When $\alpha=0$, deterioration of items is switched off, when $\beta=1, \theta(\mathrm{t})$ becomes a constant, when $\beta<1$, the rate of deterioration is decreasing with time $\mathrm{t}$ and when $\beta>1$, the rate of deterioration is increasing with time t.

(vii). The demand rate $\mathrm{D}(\mathrm{t})$ is assumed to be a ramp type function of time

$$
\mathrm{D}(\mathrm{t})=D_{0}[t-(t-\mu) H(t-\mu)], D_{0}>0,
$$

where the well-known Heavisides' function $H(t-\mu)$ is defined as

$$
H(t-\mu)=\left\{\begin{array}{l}
1, t \geq \mu \\
0, t<\mu
\end{array}\right. \text { (see figure 1). }
$$

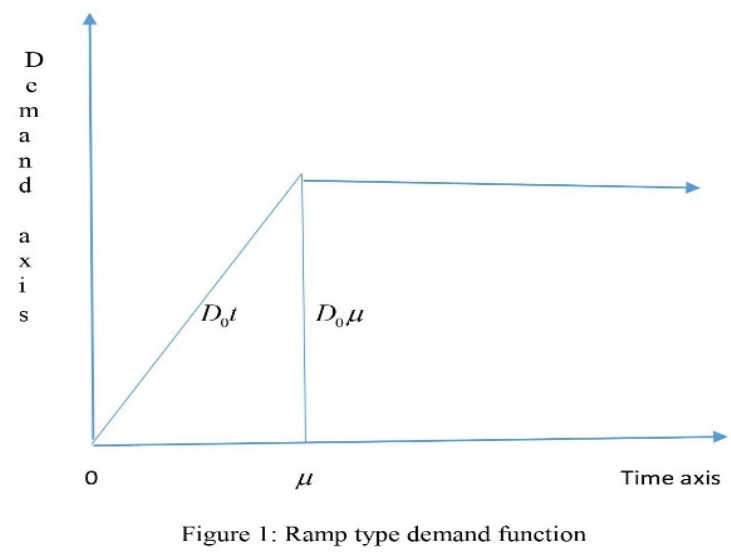

(viii). Shortages are allowed and fully backlogged.

\section{Notations:}

The following notations are made:

(i) $\quad \mathrm{q}(\mathrm{t})$ : On hand inventory at time $\mathrm{t}$.

(ii) $\mathrm{T}$ : The fixed length of each production cycle.

(iii) $\mathrm{S}$ : The size of initial inventory

(iv) $\quad \mathrm{Q}$ : The total amount of on-hand inventory.

(v) $t_{1}:$ Length of the period with positive stock of the items.

(vi) $\quad t_{c} \quad$ : Allowable trade credit period during settling the account.

(vii) $C_{0}:$ The ordering cost per order during the cycle period.

(viii) $\mathrm{c}$ : The unit cost per item.

(ix) $\quad c_{h}$ : The holding cost per unit item.

(x) $\quad c_{s}:$ The shortage cost per unit item.

(xi) $I_{e}:$ The interest earned per unit time,

(xii) $I_{p}:$ The interest paid per unit time,

(xii) $C_{O}:$ The total ordering cost over the cycle period.

(xiv) $C_{D}:$ Cost due to deterioration over the cycle period,

(xv) $C_{H}$ : Holding cost over the cycle period,

(xvi) $C_{S}$ : Cost due to shortage over the cycle period,

(xvii) $\quad P_{T}:$ Total Interest payable over the cycle period, 
(xviii) $I_{T}:$ Total Interest earned over the cycle period,

(xix) TC : Total average inventory cost per unit time.

\section{Model development:}

Let $\mathrm{Q}$ be the total amount of inventory purchased or produced at the beginning of each period and $\mathrm{S}(>0)$ be the initial inventory assumed after fulfilling backorders. During $\left[0, t_{1}\right]$, the stock will be gradually depleted due to the effect of deterioration and market demand, and ultimately falls to zero at $\mathrm{t}=t_{1}$. The shortages occur during time period $\left[t_{1}, \mathrm{~T}\right]$ which are fully backlogged. The instantaneous state of the inventory level $\mathrm{q}(\mathrm{t})$ at time $\mathrm{t}$ governed by the following equations

$$
\begin{aligned}
& \qquad \begin{array}{l}
\frac{d q(t)}{d t}+\theta(t) q(t)=-D(t), 0 \leq t \leq t_{1} \\
\text { And } \frac{d q(t)}{d t}=-D(t), t_{1} \leq t \leq T
\end{array}
\end{aligned}
$$

The boundary conditions are $q(0)=S$ and $q\left(t_{1}\right)=0$

In the present model, we assume $\mu<t_{1}$ and so the above two equations become

$$
\begin{aligned}
& \frac{d q(t)}{d t}+\alpha \beta t^{\beta-1} q(t)=-D_{0} t, 0 \leq t \leq \mu \\
& \frac{d q(t)}{d t}+\alpha \beta t^{\beta-1} q(t)=-D_{0} \mu, \mu \leq t \leq t_{1} \\
& \text { and } \frac{d q(t)}{d t}=-D_{0} \mu, t_{1} \leq t \leq T
\end{aligned}
$$

As $0 \leq \alpha<<1$, we ignore the terms of $\mathrm{O}\left(\alpha^{2}\right)$, and using the boundary conditions (3.3) we get the following solutions of the above equations (3.4), (3.5) and (3.6)

$$
\begin{gathered}
q(t)=S\left(1-\alpha t^{\beta}\right)-\frac{D_{0} t^{2}}{2}\left[1-\frac{\alpha \beta}{\beta+2} t^{\beta}\right], 0 \leq t \leq \mu \\
q(t)=S\left(1-\alpha t^{\beta}\right)-D_{0} \mu t\left[1-\frac{\alpha \beta}{\beta+1} t^{\beta}\right]+\frac{D_{0} \mu^{2}}{2}\left[1-\alpha t^{\beta}+\frac{2 \alpha \mu^{\beta}}{(\beta+1)(\beta+2)}\right], \mu \leq t \leq t_{1}
\end{gathered}
$$

and $q(t)=-D_{0} \mu\left(t-t_{1}\right), t_{1} \leq t \leq T$

Since $q\left(t_{1}\right)=0$, we get from the equation (3.8) the following (neglecting second and higher order terms of $\alpha(<<1)$

$$
S=D_{0} \mu t_{1}\left(1+\frac{\alpha}{\beta+1} t_{1}^{\beta}\right)-\frac{D_{0} \mu^{2}}{2}\left[1+\frac{2 \alpha \mu^{\beta}}{(\beta+1)(\beta+2)}\right]
$$

Therefore the total amount of on-hand inventory over the entire cycle $(0, \mathrm{~T})$ is

$$
Q=S+\int_{t_{1}}^{T} D(t) d t=S+\int_{t_{1}}^{T} D_{0} \mu d t=S+D_{0} \mu\left(T-t_{1}\right)
$$

Putting the value of S obtained from (3.10), we get the following 


$$
Q=D_{0} \mu\left[T-\frac{\mu}{2}+\frac{\alpha}{\beta+1} t_{1}^{\beta+1}-\frac{\alpha \mu^{\beta+1}}{(\beta+1)(\beta+2)}\right]
$$

\section{Inventory Scenarios :}

Regarding interests charged and earned the following three distinct cases are considered due to the total depletion of the on-hand inventory at time $t_{1}(<T)$

Case I : $t_{c} \leq \mu \leq t_{1}<T$

Cae II : $\mu \leq t_{c} \leq t_{1}<T$

and Case III : $\mu \leq t_{1} \leq t_{c}<T$
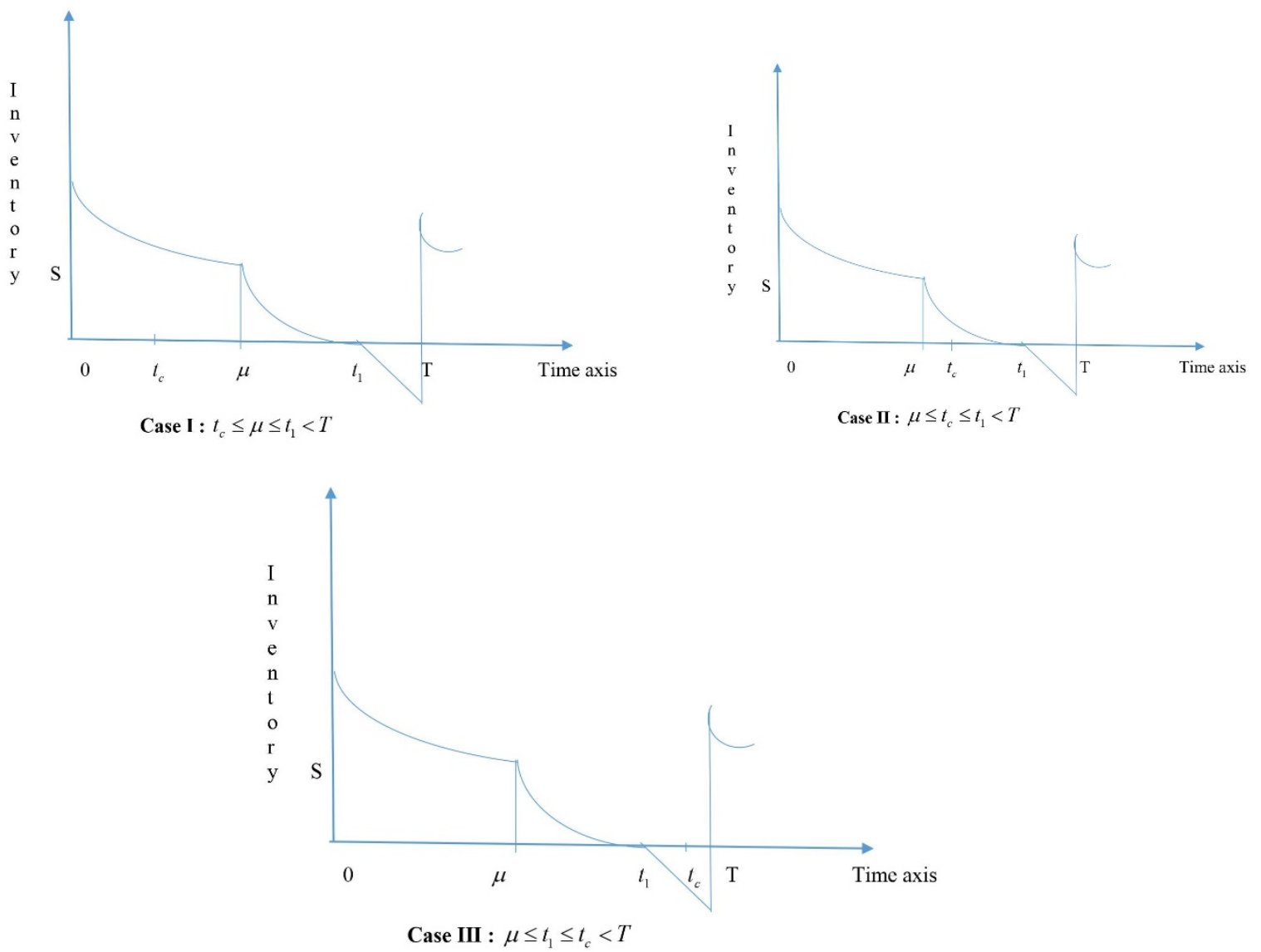

The total interest payable over the entire cycle $(0, \mathrm{~T})$ is

$$
P_{T}=\left|\begin{array}{l}
I P_{1}, t_{c} \leq \mu \leq t_{1}<T \\
I P_{2}, \mu \leq t_{c} \leq t_{1}<T \\
I P_{3}, \mu \leq t_{1} \leq t_{c}<T
\end{array}\right|
$$

The total interest earned over the entire cycle $(0, \mathrm{~T})$ is

$$
I_{T}=\left|\begin{array}{l}
I E_{1}, t_{c} \leq \mu \leq t_{1}<T \\
I E_{2}, \mu \leq t_{c} \leq t_{1}<T \\
I E_{3}, \mu \leq t_{1} \leq t_{c}<T
\end{array}\right|
$$


The total average cost of the system per unit time is given by

$$
T C=\left|\begin{array}{l}
T C_{1}, t_{c} \leq \mu \leq t_{1}<T \\
T C_{2}, \mu \leq t_{c} \leq t_{1}<T \\
T C_{3}, \mu \leq t_{1} \leq t_{c}<T
\end{array}\right|
$$

\section{Cost Components:}

The total inventory cost during the period $[0, \mathrm{~T}]$ contains the following cost components:

(1). Ordering cost $\left(C_{O}\right)$ during the period $[0, \mathrm{~T}]=C_{0}$ (fixed)

(2). Cost due to deterioration $\left(C_{D}\right)$ during the period $[0, \mathrm{~T}]=\mathrm{cQ}$

$$
=c D_{0} \mu\left[T-\frac{\mu}{2}+\frac{\alpha}{\beta+1} t_{1}^{\beta+1}-\frac{\alpha \mu^{\beta+1}}{(\beta+1)(\beta+2)}\right]
$$

(3). Holding cost for carrying inventory $\left(C_{H}\right)$ during the period $[0, \mathrm{~T}]$

$$
\begin{gathered}
C_{H}=c c_{h} \int_{0}^{t_{1}} q(t) d t=c c_{h}\left[\int_{0}^{\mu} q(t) d t+\int_{\mu}^{t_{1}} q(t) d t\right] \\
=c c_{h} D_{0}\left[\frac{t_{1}^{2}}{2}-\frac{\mu^{2}}{6}+\frac{\alpha \beta}{(\beta+1)(\beta+2)} t_{1}^{\beta+2}-\frac{\alpha \beta \mu^{\beta+2}}{(\beta+1)(\beta+2)(\beta+3)}\right]
\end{gathered}
$$

(4). Cost due to shortage $\left(C_{S}\right)$ during the period $[0, \mathrm{~T}]$

$$
C_{S}=c_{s} \int_{t_{1}}^{T} D(t)(T-t) d t=c_{s} D_{0} \frac{\mu}{2}\left(T-t_{1}\right)^{2}
$$

Case I : $\quad t_{c} \leq \mu \leq t_{1}<T$

The total interest payable $\left(P_{T}=I P_{1}\right)$ during the period $[0, \mathrm{~T}]$

$$
\begin{aligned}
= & c I_{P} \int_{t_{c}}^{t_{1}} q(t) d t=c I_{P}\left[\int_{t_{c}}^{\mu} q(t) d t+\int_{\mu}^{t_{1}} q(t) d t\right] \\
= & c I_{p} D_{0}\left[-\frac{\mu^{3}}{3}-\frac{\alpha \beta \mu^{\beta+3}}{(\beta+1)(\beta+2)(\beta+3)}-\mu t_{c} t_{1}+\frac{\mu^{2}}{2} t_{c}-\frac{\alpha \mu}{\beta+1} t_{c} t_{1}^{\beta+1}+\frac{\alpha \mu^{\beta+2}}{(\beta+1)(\beta+2)} t_{c}+\frac{\alpha \mu}{\beta+1} t_{c}^{\beta+1} t_{1}\right. \\
& \left.-\frac{\alpha \mu^{2}}{2(\beta+1)} t_{c}^{\beta+1}+\frac{t_{c}^{3}}{6}-\frac{\alpha \beta}{2(\beta+2)(\beta+3)} t_{c}^{\beta+3}+\frac{\mu t_{1}^{2}}{2}+\frac{\alpha \beta}{(\beta+1)(\beta+2)} \mu t_{1}^{\beta+2}\right]
\end{aligned}
$$

The total interest earned ( $\left.I_{T}=I E_{1}\right)$ during the period $[0, \mathrm{~T}]$

$$
\begin{aligned}
& =c I_{e} \int_{0}^{t_{1}} D(t) t d t=c I_{e}\left[\int_{0}^{\mu} D_{0} t^{2} d t+\int_{\mu}^{t_{1}} D_{0} \mu t d t\right] \\
& =c I_{e} D_{0} \frac{\mu}{2}\left(t_{1}^{2}-\frac{\mu^{2}}{3}\right)
\end{aligned}
$$


The average total inventory cost per unit time is given by the following

$$
\begin{gathered}
T C_{1}\left(t_{1}\right)=\frac{1}{T}\left[C_{O}+C_{D}+C_{H}+C_{S}+I P_{1}-I E_{1}\right] \\
=\frac{1}{T} \quad \mathrm{I} \quad C_{0}+D_{0} \mu\left[T-\frac{\mu}{2}+\frac{\alpha}{\beta+1} t_{1}^{\beta+1}-\frac{\alpha \mu^{\beta+1}}{(\beta+1)(\beta+2)}\right] \\
c c_{h} D_{0}\left[\frac{t_{1}^{2}}{2}-\frac{\mu^{2}}{6}+\frac{\alpha \beta}{(\beta+1)(\beta+2)} t_{1}^{\beta+2}-\frac{\alpha \beta \mu^{\beta+2}}{(\beta+1)(\beta+2)(\beta+3)}\right]+c_{s} D_{0} \frac{\mu}{2}\left(T-t_{1}\right)^{2}+ \\
c I_{p} D_{0}\left[-\frac{\mu^{3}}{3}-\frac{\alpha \beta \mu^{\beta+3}}{(\beta+1)(\beta+2)(\beta+3)}-\mu t_{c} t_{1}+\frac{\mu^{2}}{2} t_{c}-\frac{\alpha \mu}{\beta+1} t_{c} t_{1}^{\beta+1}+\frac{\alpha \mu^{\beta+2}}{(\beta+1)(\beta+2)} t_{c}+\frac{\alpha \mu}{\beta+1} t_{c}^{\beta+1} t_{1}\right. \\
\left.\left.-\frac{\alpha \mu^{2}}{2(\beta+1)} t_{c}^{\beta+1}+\frac{t_{c}^{3}}{6}-\frac{\alpha \beta}{2(\beta+2)(\beta+3)} t_{c}^{\beta+3}+\frac{\mu t_{1}^{2}}{2}+\frac{\alpha \beta}{(\beta+1)(\beta+2)} \mu t_{1}^{\beta+2}\right]-c I_{e} D_{0} \frac{\mu}{2}\left(t_{1}^{2}-\frac{\mu^{2}}{3}\right)\right]
\end{gathered}
$$

The necessary condition for the minimization of the average cost $T C_{1}\left(t_{1}\right)$ is

$$
\frac{d T C_{1}\left(t_{1}\right)}{d t_{1}}=0
$$

After little calculation, the following non-linear equation in $t_{1}$ is

$$
A_{1} t_{1}^{\beta+1}+B_{1} t_{1}^{\beta}+C_{1} t_{1}+D_{1}=0
$$

where $A_{1}=\frac{c \alpha \beta}{\beta+1}\left(c_{h}+\mu I_{p}\right), \quad B_{1}=c \mu \alpha\left(1-I_{p} t_{c}\right), C_{1}=\left\{c c_{h}+c \mu\left(I_{p}-I_{e}\right)+c_{s}\right\}$

$$
\text { and } D_{1}=-c I_{p} \mu t_{c}+c I_{p} \frac{\alpha \mu}{\beta+1} t_{c}^{\beta+1}-c_{s} T
$$

For minimum, the sufficient condition $\frac{\mathrm{d}^{2} \mathrm{TC}_{1}\left(\mathrm{t}_{1}\right)}{\mathrm{dt}_{1}{ }^{2}}>0$ would be satisfied.

The optimal values $S^{*}$ of S, $Q^{*}$ of $\mathrm{Q}$ and $T C_{1}^{*}$ of $T C_{1}$ are obtained by putting the optimal value $t_{1}=t_{1}^{*}$ from the expressions (3.10), (3.11) and (4.1).

Case II : $\quad \mu \leq t_{c} \leq t_{1}<T$

The total interest payable $\left(P_{T}=I P_{2}\right)$ during the period $[0, \mathrm{~T}]$

$$
\begin{gathered}
=c I_{p} \int_{t_{c}}^{t_{1}} q(t) d t \\
c I_{p} D_{0} \mu\left[\frac{t_{1}^{2}}{2}-t_{c} t_{1}+\frac{t_{c}^{2}}{2}+\frac{\alpha}{\beta+1} t_{c}^{\beta+1} t_{1}-\frac{\alpha}{\beta+1} t_{c} t_{1}^{\beta+1}+\frac{\alpha \beta}{(\beta+1)(\beta+2)} t_{1}^{\beta+1}-\frac{\alpha \beta}{(\beta+1)(\beta+2)} t_{c}^{\beta+2}\right]
\end{gathered}
$$

The total interest earned $\left(I_{T}=I E_{2}\right)$ during the period $[0, \mathrm{~T}]$

$$
\begin{aligned}
& =c I_{e} \int_{0}^{t_{1}} D(t) t d t=c I_{e}\left[\int_{0}^{\mu} D_{0} t^{2} d t+\int_{\mu}^{t_{1}} D_{0} \mu t d t\right] \\
& =c I_{e} D_{0} \frac{\mu}{2}\left(t_{1}^{2}-\frac{\mu^{2}}{3}\right)
\end{aligned}
$$

The average total inventory cost per unit time is given by the following 


$$
\begin{gathered}
T C_{2}\left(t_{1}\right)=\frac{1}{T}\left[C_{O}+C_{D}+C_{H}+C_{S}+I P_{2}-I E_{2}\right] \\
=\frac{1}{T} \quad\left[\quad C_{0}+D_{0} \mu\left[T-\frac{\mu}{2}+\frac{\alpha}{\beta+1} t_{1}^{\beta+1}-\frac{\alpha \mu^{\beta+1}}{(\beta+1)(\beta+2)}\right]+\right. \\
c c_{h} D_{0}\left[\frac{t_{1}^{2}}{2}-\frac{\mu^{2}}{6}+\frac{\alpha \beta}{(\beta+1)(\beta+2)} t_{1}^{\beta+2}-\frac{\alpha \beta \mu^{\beta+2}}{(\beta+1)(\beta+2)(\beta+3)}\right]+c_{s} D_{0} \frac{\mu}{2}\left(T-t_{1}\right)^{2}+ \\
c I_{p} D_{0} \mu\left[\frac{t_{1}^{2}}{2}-t_{c} t_{1}+\frac{t_{c}^{2}}{2}+\frac{\alpha}{\beta+1} t_{c}^{\beta+1} t_{1}-\frac{\alpha}{\beta+1} t_{c} t_{1}^{\beta+1}+\frac{\alpha \beta}{(\beta+1)(\beta+2)} t_{1}^{\beta+1}-\frac{\alpha \beta}{(\beta+1)(\beta+2)} t_{c}^{\beta+2}\right] \\
\left.-c I_{e} D_{0} \frac{\mu}{2}\left(t_{1}^{2}-\frac{\mu^{2}}{3}\right)\right]
\end{gathered}
$$

The necessary condition for the minimization of the average cost $T C_{2}\left(t_{1}\right)$ is

$$
\frac{d T C_{2}\left(t_{1}\right)}{d t_{1}}=0
$$

After little calculation, the following non-linear equation in $t_{1}$ is

$$
A_{2} t_{1}^{\beta+1}+B_{2} t_{1}^{\beta}+C_{2} t_{1}+D_{2}=0
$$

Where $A_{2}=\frac{c \alpha \beta}{\beta+1}\left(c_{h}+\mu I_{p}\right), \quad B_{2}=c \mu \alpha\left(1-I_{p} t_{c}\right), C_{2}=\left\{c c_{h}+c \mu\left(I_{p}-I_{e}\right)+c_{s}\right\}$

$$
\text { and } D_{2}=-c I_{p} \mu t_{c}+c I_{p} \frac{\alpha \mu}{\beta+1} t_{c}^{\beta+1}-c_{s} T
$$

For minimum, the sufficient condition $\frac{\mathrm{d}^{2} \mathrm{TC}_{2}\left(\mathrm{t}_{1}\right)}{\mathrm{dt}_{1}^{2}}>0$ would be satisfied.

The optimal values $S^{*}$ of S, $Q^{*}$ of $\mathrm{Q}$ and $T C_{2}^{*}$ of $T C_{2}$ are obtained by putting the optimal value $t_{1}$ obtained from the expressions (3.10), (3.11) and (4.3).

Case III : $\mu \leq t_{1} \leq t_{c}<T$

In this case, the retailer pays the procurement cost to the supplier prior to expiration of the trade credit period $t_{c}$ provided by the buyer. Hence, there will be no the interest charged $\left(I P_{3}=0\right)$ for the items kept in stock. Since the credit period is greater than the depletion time of inventory, the interest earned during the period $[0, \mathrm{~T}]$ is given by the following

$$
\begin{aligned}
I E_{3} & =c I_{e} \int_{0}^{t_{1}} t D(t) d t+c I_{e}\left(t_{c}-t_{1}\right) \int_{0}^{t_{1}} D(t) d t \\
& =c I_{e}\left[\int_{0}^{\mu} D_{0} t^{2} d t+\int_{\mu}^{t_{1}} D_{0} \mu t d t\right]+c I_{e}\left(t_{c}-t_{1}\right)\left[\int_{0}^{\mu} D_{0} t d t+\int_{\mu}^{t_{1}} D_{0} \mu d t\right] \\
& =c I_{e} D_{0} \mu\left[\frac{t_{1}^{2}}{2}-\frac{\mu^{2}}{6}+\left(t_{c}-t_{1}\right)\left(t_{1}-\frac{\mu}{2}\right)\right]
\end{aligned}
$$

The total average inventory cost during the period $[0, \mathrm{~T}]$ is given by the following 


$$
\begin{aligned}
& T C_{3}\left(t_{1}\right)=\frac{1}{T}\left[C_{O}+C_{D}+C_{H}+C_{S}+I P_{3}-I E_{3}\right] \\
&=\frac{1}{T} \quad\left[\quad C_{0}+D_{0} \mu\left[T-\frac{\mu}{2}+\frac{\alpha}{\beta+1} t_{1}^{\beta+1}-\frac{\alpha \mu^{\beta+1}}{(\beta+1)(\beta+2)}\right]+\right. \\
& c c_{h} D_{0}\left[\frac{t_{1}^{2}}{2}-\frac{\mu^{2}}{6}+\frac{\alpha \beta}{(\beta+1)(\beta+2)} t_{1}^{\beta+2}-\frac{\alpha \beta \mu^{\beta+2}}{(\beta+1)(\beta+2)(\beta+3)}\right]+c_{s} D_{0} \frac{\mu}{2}\left(T-t_{1}\right)^{2}+ \\
&\left.-c I_{e} D_{0} \mu\left[\frac{t_{1}^{2}}{2}-\frac{\mu^{2}}{6}+\left(t_{c}-t_{1}\right)\left(t_{1}-\frac{\mu}{2}\right)\right]\right]
\end{aligned}
$$

By the similar procedure as in case I and case II, the optimality equation $\frac{d T C_{3}\left(t_{1}\right)}{d t_{1}}=0$ yields

$$
A_{3} t_{1}^{\beta+1}+B_{3} t_{1}^{\beta}+C_{3} t_{1}+D_{3}=0
$$

where $A_{3}=\frac{c c_{h} \alpha \beta}{\beta+1}, B_{3}=c \mu \alpha, C_{3}=c\left(c_{h}+\mu I_{e}\right)+c_{s}$ and $D_{3}=-c \mu I_{e}\left(\frac{\mu}{2}+t_{c}\right)-c_{s} T$

The above equation can be solved to find the optimal values of $t_{1}$, and then the optimal values of $\mathrm{S}, \mathrm{Q}$ and $T C_{3}$ can be obtained from the expressions (3.10), (3.11) and (4.5) respectively.

\section{Some particular cases:}

a) If the deterioration of the items is switched off i.e. $\alpha=0$, then the equations (4.2), (4.4) and (4.6) for the above mentioned cases become

$$
\begin{aligned}
t_{1} & =-\frac{D_{1}}{C_{1}}, \text { where } C_{1}=\left\{c c_{h}+c \mu\left(I_{p}-I_{e}\right)+c_{s}\right\} \text { and } D_{1}=-\left(c I_{p} \mu t_{c}+c_{s} T\right) \\
t_{1} & =-\frac{D_{2}}{C_{2}}, \text { where } C_{2}=\left\{c c_{h}+c \mu\left(I_{p}-I_{e}\right)+c_{s}\right\} \text { and } D_{2}=-\left(c I_{p} \mu t_{c}+c_{s} T\right) \\
\text { and } t_{1} & =-\frac{D_{3}}{C_{3}}, \text { where } C_{3}=c\left(c_{h}+\mu I_{e}\right)+c_{s} \text { and } D_{3}=-c \mu I_{e}\left(\frac{\mu}{2}+t_{c}\right)-c_{s} T
\end{aligned}
$$

The optimum values of $t_{1}$ obtained from (5.1), (5.2) and (5.3) give the optimum values of S, Q and TC for the three cases.

b) If the deterioration rate is constant i.e. $\beta=1$, then the equations (4.2), (4.4) and (4.6) for the above mentioned cases become

$$
A_{1} t_{1}^{2}+\left(B_{1}+C_{1}\right) t_{1}+D_{1}=0
$$

where $A_{1}=\frac{c \alpha}{2}\left(c_{h}+\mu I_{p}\right), \quad B_{1}=c \mu \alpha\left(1-I_{p} t_{c}\right), C_{1}=\left\{c c_{h}+c \mu\left(I_{p}-I_{e}\right)+c_{s}\right\}$

$$
\begin{aligned}
& \text { and } D_{1}=-c I_{p} \mu t_{c}+c I_{p} \frac{\alpha \mu}{2} t_{c}^{2}-c_{s} T \\
& A_{2} t_{1}^{2}+\left(B_{2}+C_{2}\right) t_{1}+D_{2}=0
\end{aligned}
$$

where $A_{2}=\frac{c \alpha}{2}\left(c_{h}+\mu I_{p}\right), B_{2}=c \mu \alpha\left(1-I_{p} t_{c}\right), C_{2}=\left\{c c_{h}+c \mu\left(I_{p}-I_{e}\right)+c_{s}\right\}$ 


$$
\begin{aligned}
& \text { and } D_{2}=-c I_{p} \mu t_{c}+c I_{p} \frac{\alpha \mu}{2} t_{c}^{2}-c_{s} T \\
& \text { And } \quad A_{3} t_{1}^{2}+\left(B_{3}+C_{3}\right) t_{1}+D_{3}=0
\end{aligned}
$$

where $A_{3}=\frac{c c_{h} \alpha}{2}, B_{3}=c \mu \alpha, C_{3}=c\left(c_{h}+\mu I_{e}\right)+c_{s}$ and $D_{3}=-c \mu I_{e}\left(\frac{\mu}{2}+t_{c}\right)-c_{s} T$

The optimum values of $t_{1}$ obtained from (5.2), (5.4) and (5.6) give the optimum values of S, Q and TC for the three cases.

\section{Numerical Examples:}

To illustrate the preceding inventory model, the following examples are considered for the three inventory scenarios namely case I, case II and case III. The values of the parameters be as follows

$C_{0}=\$ 200$ per order, $D_{0}=100$ units, $c_{h}=\$ 0.12$ per unit, $c_{s}=\$ 10$ per unit, $I_{p}=\$ 0.15$ per unit, $I_{e}=\$ 0.13$ per unit, $\alpha=0.001, \beta=2, \mu=0.4$ year, $\mathrm{T}=1$ year and the set of values of $t_{c}$ and $\mathrm{c}$ are assumed as $t_{c}=\{0,0.1$, $0.3,0.5,0.7,0.9\}$ years and $\mathrm{c}=\{20,40,80,100,120,150,180,200\}$ dollars/unit.

Solving the equation (4.2), (4.4) and (4.6) with the help of computer using the above parameter values, we find the following optimum outputs

Case I : $\quad t_{c} \leq \mu \leq t_{1}<T$

Table A:

\begin{tabular}{|c|c|c|c|c|c|}
\hline \multicolumn{2}{|c|}{ Changing parameters } & \multicolumn{3}{|c|}{ Optimal values } \\
\hline $\mathrm{c}$ & $t_{c}$ & $t_{1}{ }^{*}$ & $S^{*}$ & $Q^{*}$ & $T C^{*}$ \\
\hline \multirow{3}{*}{20} & 0.0 & 0.79 & 23.83 & 32.006 & 919.51 \\
& 0.1 & 0.81 & 24.22 & 32.007 & 913.45 \\
& 0.3 & 0.82 & 24.98 & 32.008 & 900.81 \\
\hline \multirow{3}{*}{40} & 0.0 & 0.66 & 18.44 & 32.003 & 1594.91 \\
& 0.1 & 0.68 & 19.07 & 32.004 & 1586.81 \\
& 0.3 & 0.71 & 20.34 & 32.005 & 1569.90 \\
\hline \multirow{3}{*}{80} & 0.0 & 0.49 & 11.75 & 32.001 & 2896.06 \\
& 0.1 & 0.52 & 12.69 & 32.002 & 2888.42 \\
& 0.3 & 0.56 & 14.59 & 32.003 & 2868.72 \\
\hline \multirow{3}{*}{100} & 0.0 & 0.44 & 9.53 & 32.001 & 3535.99 \\
& 0.1 & 0.46 & 10.58 & 32.002 & 3529.55 \\
\hline
\end{tabular}

Case II : $\mu \leq t_{c} \leq t_{1}<T$

Table B:

\begin{tabular}{|c|c|c|c|c|c|}
\hline \multicolumn{2}{|c|}{ Changing parameters } & \multicolumn{4}{|c|}{ Optimal values } \\
\hline $\mathrm{c}$ & $t_{c}$ & $t_{1}^{*}$ & $S^{*}$ & $Q^{*}$ & $T C^{*}$ \\
\hline \multirow{3}{*}{20} & 0.5 & 0.84 & 25.74 & 32.007 & 887.50 \\
& 0.6 & 0.85 & 26.13 & 32.008 & 880.59 \\
\hline \multirow{3}{*}{40} & 0.8 & 0.87 & 26.89 & 32.009 & 866.27 \\
& 0.5 & 0.74 & 21.61 & 32.005 & 1549.10 \\
& 0.6 & 0.76 & 22.24 & 32.006 & 1538.34 \\
\hline \multirow{3}{*}{100} & 0.8 & $* *$ & $* *$ & $* *$ & 2843.13 \\
& 0.5 & 0.61 & 16.48 & 32.003 & 2828.13 \\
\hline & 0.6 & 0.64 & 17.43 & 32.004 & $* *$ \\
\hline
\end{tabular}


Case III : $\mu \leq t_{1} \leq t_{c}<T$

Table C:

\begin{tabular}{|c|c|c|c|c|c|}
\hline \multicolumn{2}{|c|}{ Changing parameters } & \multicolumn{4}{|c|}{ Optimal values } \\
\hline $\mathrm{c}$ & $t_{c}$ & $t_{1}^{*}$ & $S^{*}$ & $Q^{*}$ & $T C^{*}$ \\
\hline \multirow{2}{*}{120} & 0.5 & 0.47 & 10.74 & 32.001 & 4071.88 \\
& 0.6 & 0.49 & 11.56 & 32.002 & 4031.97 \\
& 0.8 & 0.53 & 13.18 & 32.003 & 3954.43 \\
\hline \multirow{3}{*}{150} & 0.5 & 0.43 & 9.26 & 32.001 & 4974.93 \\
& 0.6 & 0.45 & 10.13 & 32.002 & 4926.39 \\
& 0.8 & 0.50 & 11.87 & 32.003 & 4832.43 \\
\hline \multirow{3}{*}{180} & 0.5 & 0.40 & 8.15 & 32.001 & 5872.46 \\
& 0.6 & 0.43 & 9.07 & 32.002 & 5815.31 \\
& 0.8 & 0.47 & 10.89 & 32.003 & 5705.18 \\
\hline \multirow{3}{*}{200} & 0.5 & $* *$ & $*$ & $* *$ & $* *$ \\
& 0.6 & 0.41 & 8.91 & 32.001 & 6406.03 \\
& 0.8 & 0.46 & 10.36 & 32.002 & 6285.03 \\
\hline
\end{tabular}

(** indicates the infeasible solution)

\section{Numerical illustration for the particular cases:}

Considering the same parametric values as mentioned above, we find the optimum values for the particular cases as follows

Table-D

\begin{tabular}{|c|c|c|c|c|c|c|c|}
\hline \multirow{2}{*}{ Particular cases } & \multirow{2}{*}{$\begin{array}{c}\text { Inventory } \\
\text { scenarios }\end{array}$} & \multicolumn{2}{|c|}{$\begin{array}{c}\text { Changing } \\
\text { parameters }\end{array}$} & \multicolumn{4}{c|}{ Optimal values } \\
\cline { 3 - 8 } & & $\mathrm{c}$ & $t_{c}$ & $t_{1}^{*}$ & $S^{*}$ & $Q^{*}$ & $T C^{*}$ \\
\cline { 3 - 8 } & Case I & 20 & 0.1 & 0.81 & 24.23 & 31.999 & 913.36 \\
Absence of & Case II & 20 & 0.5 & 0.84 & 25.76 & 32.000 & 887.38 \\
deterioration & Case III & 120 & 0.5 & 0.47 & 10.76 & 31.999 & 4164.36 \\
& & & & & & & \\
\hline & Case I & 20 & 0.1 & 0.81 & 24.22 & 32.012 & 913.56 \\
Constant rate of & Case II & 20 & 0.5 & 0.84 & 25.75 & 32.014 & 887.61 \\
deterioration & Case III & 120 & 0.5 & 0.47 & 10.75 & 32.004 & 4164.30 \\
& & & & & & & \\
\hline
\end{tabular}

\section{Concluding Remarks:}

On the basis of the results shown in Table A, Table B and Table C the following observations can be made

(i) $\quad T C^{*}$ increases while $S^{*}$ and $Q^{*}$ decrease with increase in the values of the system parameter c. On the other hand $T C^{*}$ decreases while $S^{*}$ and $Q^{*}$ increase with increase in the values of the system parameter $t_{c}$. The results obtained show that $S^{*}$ and $Q^{*}$ are less sensitive and $T C^{*}$ is highly sensitive towards the changes of these parameters $\mathrm{c}$ and $t_{c}$.

(ii) It is also observed that inventory cost $\left(T C^{*}\right)$ is attained minimum mostly for the case II. Therefore when the permissible trade credit period $t_{c}$ lies between $\mu$ and $t_{1}$, the total average inventory cost attains minimum most in the proposed inventory model..

(iii) $\quad * *$ indicates the infeasible solution attained where the condition for the corresponding inventory scenario is violated.

(iv). The results obtained in Table $\mathrm{D}$ conclude that there are no major changes in the optimum values of $T C^{*}, S^{*}$ and $Q^{*}$ for the two particular cases of the inventory model assuming absence of deterioration and constant rate of deterioration. 


\section{References:}

[1]. R.P. Covert \& G.C. Philip (1973) : “An EOQ model for items with Weibull distribution deterioration”, AIIE Trans., 5, pp. 323-326.

[2]. A.K. Jalan, B.C. Giri \& K.S. Choudhuri (1996) : "EOQ model for items with Weibull distribution deterioration, shortages and trended demand", Int. J. Syst. Sci., 27(9), pp. 851-855..

[3]. T. Chackrabarty B.C. Giri \& K.S. Choudhuri (1998) : "An EOQ model for items with Weibull distribution deterioartion, shortages and trended demand", Computers and Operations Research, 25(7), pp. 649-657.

[4]. K.S.Wu (2002) : "Deterministic inventory model for items with time varying demand, Weibull distribution deterioration and shortages ", Yugoslav J. Operations Research, 12(1), pp. 61-71.

[5]. A K Sharma, M.K. Sharma \& N Ramani (2012) : “ An inventory model with Weibull distribution deteriorating power pattern demand with shortages and time dependent holding cost", American J. of Appl. Maths and Mathematical Sci., 1(1-2), pp. 17-22.

[6]. Dr. Biswaranjan Mandal (2010) "An EOQ inventory model for Weibull distributed deteriorating Items under ramp type demand and shortages", OPSEARCH, 47(2), pp.158-165.

[7]. Dr. Biswaranjan Mandal (2020) "An inventory model with time dependent demand, Weibull-distributed deterioration under salvage value and shortages", IOSR Journal of Business and Management, 22(9), pp.5964.

[8]. W. A. Donaldson (1977): "Inventory replenishment policy for a linear trend in demand-An analytical solution”, Oper. Res. Q, 28, pp. 663-670.

[9]. E. A. Silver (1979): “A simple inventory replenishment decision rule for a linear trend in demand", J. Oper. Res. Soc., 30, pp. 71-75.

[10]. R. M. Hill (1995) : "Inventory model for increasing demand followed by level demand J. Oper. Res. Soc., 46, pp. 1250-1259.

[11]. M. Mallick, S. Mishra, U. K. Mishra and S.K Paikray (2018) : "Optimal inventory control for ameliorating, deteriorating items under time varying demand condition”, Journal of Social Science Research, 3(1), pp.166-173

[12]. Dr. Biswaranjan Mandal (2020) : “An inventory management system for deteriorating items with ramp type and quadratic demand: a structural comparative study", International Journal on Soft Computing (IJSC), 11(1-4), pp. 1-8

[13]. S.P. Aggarwal \& C.K. Jaggi (1995) : “Ordering policies of deteriorating items under permissible delay in payment”, J. Opl. Res. Soc., 46, pp. 658-662.

[14]. H.J. Chang, D. Chung-Yuan (2002): "An inventory model for deteriorating items under the condition of permissible delay in payments", Production Planning and Control, 12(3), pp. 73-83

[15]. Y.F. Huang (2007): "Economic order quantity under conditionally permissible delay in payments", European Journal of Operational Research, 176(2), pp. 911-924.

[16]. H.C. Chang, (2009), "The optimal pricing and ordering policy for an integrated inventory model when trade credit linked to order quantity", Applied Mathematical Modeling, 33, 7, pp.2978-2991.

[17]. G. Li, Y. Kang, M. Liu and Z. Wang (2014) : "Optimal inventory policy under permissible payment delay in fashion supply chains", Mathematical Problems in Engineering, http://dx.doi.org/10.1155/2014/327131, pp. 1-9.

[18]. N. P. Behera \& P. K. Tripathy(2017) : “An optimal replenishment policy for deteriorating items with power pattern under permissible delay in payments”, International Journal of Statistics and Systems, ISSN 09732675, 12(3), pp. 457-474.

[19]. Dr. Biswaranjan Mandal (2021): "Replenishment policy for deteriorating items with additive exponential life time under permissible delay in payment", International Journal of Advanced Research in Science, Engineering and Technology, 8(7), pp. 17649-17656. 